\title{
Cytokines in Systemic Lupus Erythematosus 2011
}

\author{
Brian D. Poole, ${ }^{1}$ Timothy B. Niewold, ${ }^{2}$ and George C. Tsokos ${ }^{3}$ \\ ${ }^{1}$ Department of Microbiology and Molecular Biology, Brigham Young University, Provo, UT 84602, USA \\ ${ }^{2}$ Department of Medicine, University of Chicago, Chicago, IL 60637, USA \\ ${ }^{3}$ Division of Rheumatology, Beth Israel Deaconess Medical Center, Harvard Medical School, Boston, MA 02215, USA \\ Correspondence should be addressed to Brian D. Poole, bpoole@gmail.com
}

Received 7 December 2011; Accepted 7 December 2011

Copyright (c) 2012 Brian D. Poole et al. This is an open access article distributed under the Creative Commons Attribution License, which permits unrestricted use, distribution, and reproduction in any medium, provided the original work is properly cited.

With the BLyS inhibitor Belimumab recently approved by the United States Food and Drug administration as the first treatment for Systemic Lupus Erythematosus in decades, and the ongoing trials of other cytokine inhibitors as potential therapeutic agents for lupus, the potential of cytokines in the realm of therapeutic targets for lupus is beginning to reach its promise. These fascinating molecules regulate multiple facets of the immune system and, as such, have been extensively examined for a role in many different aspects of lupus etiology, pathogenesis, and regulation.

This special issue contains novel research about three cytokines and their roles in lupus. Alleles of Osteopontin were found to be associated with multiple clinical manifestations of lupus (T. Trivedi et al.). The feasibility of Neutrophil gelatinase-associated lipocalin as a biomarker for kidney damage was assessed (Y.-L. Yang et al.). The lupus risk haplotype of the Interferon regulatory factor five gene was found to influence gene expression in three key pathways that have the potential to influence the development or pathogenesis of lupus (J. M. Guthridge et al.).

The reviews included in this issue summarize the most current research on the multiple roles of cytokines in lupus (K. Ohl and K. Tenbrock). The influences of cytokines on $\mathrm{T}$ cell subsets in lupus and how those subsets relate to lupus are discussed (A. Okamoto et al., K. Miyake et al.). The roles of cytokines in clinical manifestations, such as nephritis (Y. Iwata et al.), neuropsychiatric manifestations, cutaneous lupus, and premature atherosclerosis (T. P. Karageorgas et al.), are a major focus of this issue.

Cytokine research holds tremendous promise for understanding and treating lupus. We thank all those who contributed articles for this special issue and those who reviewed and in other ways contributed. We hope that this avenue of research will continue to be supported and be a benefit to the lives of those suffering with this complex and difficult disease.

Brian D. Poole Timothy B. Niewold George C. Tsokos 


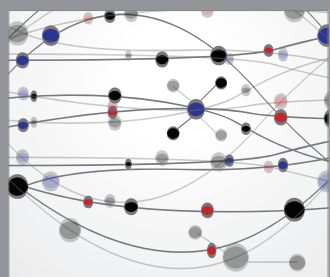

The Scientific World Journal
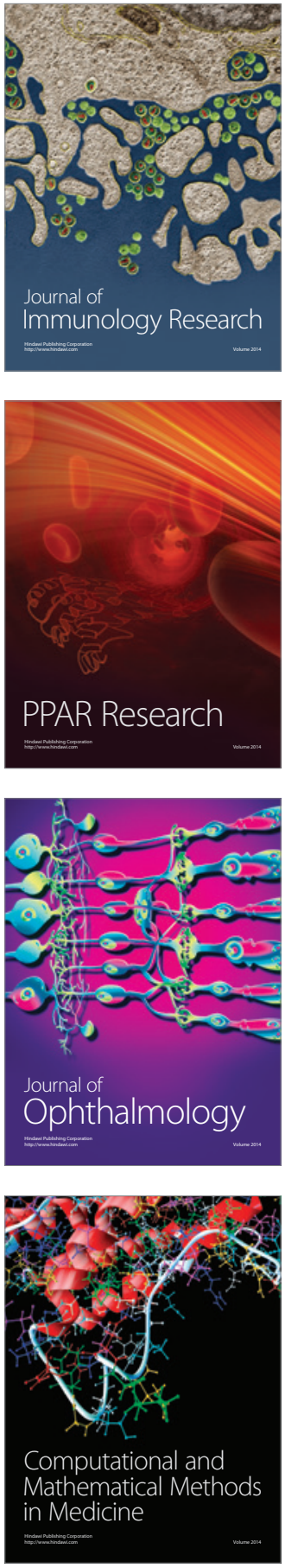

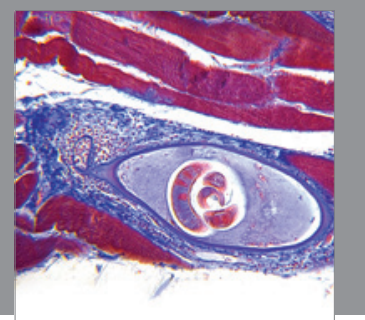

Gastroenterology

Research and Practice
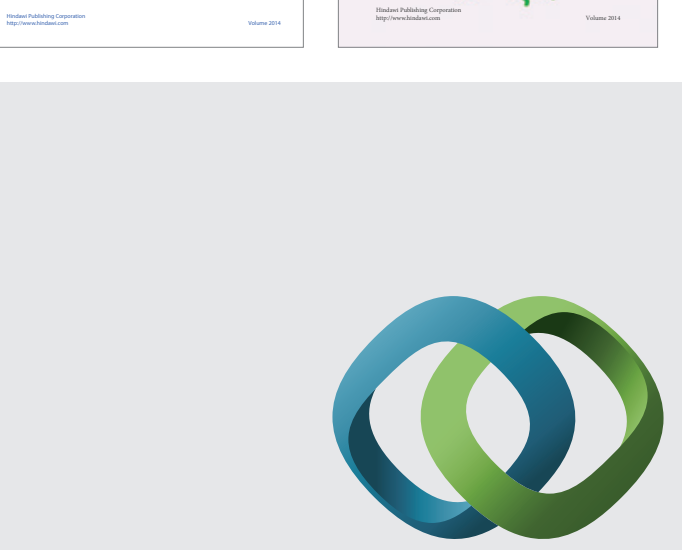

\section{Hindawi}

Submit your manuscripts at

http://www.hindawi.com
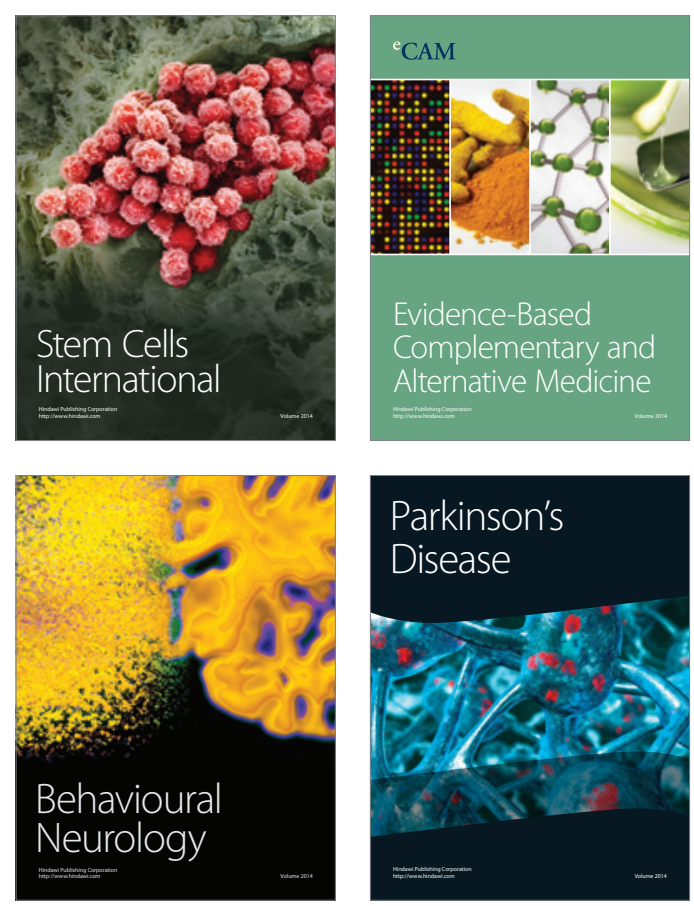

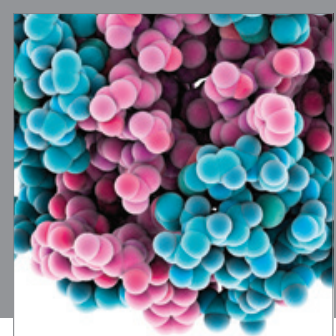

Journal of
Diabetes Research

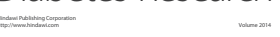

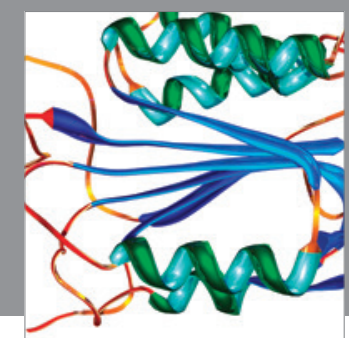

Disease Markers
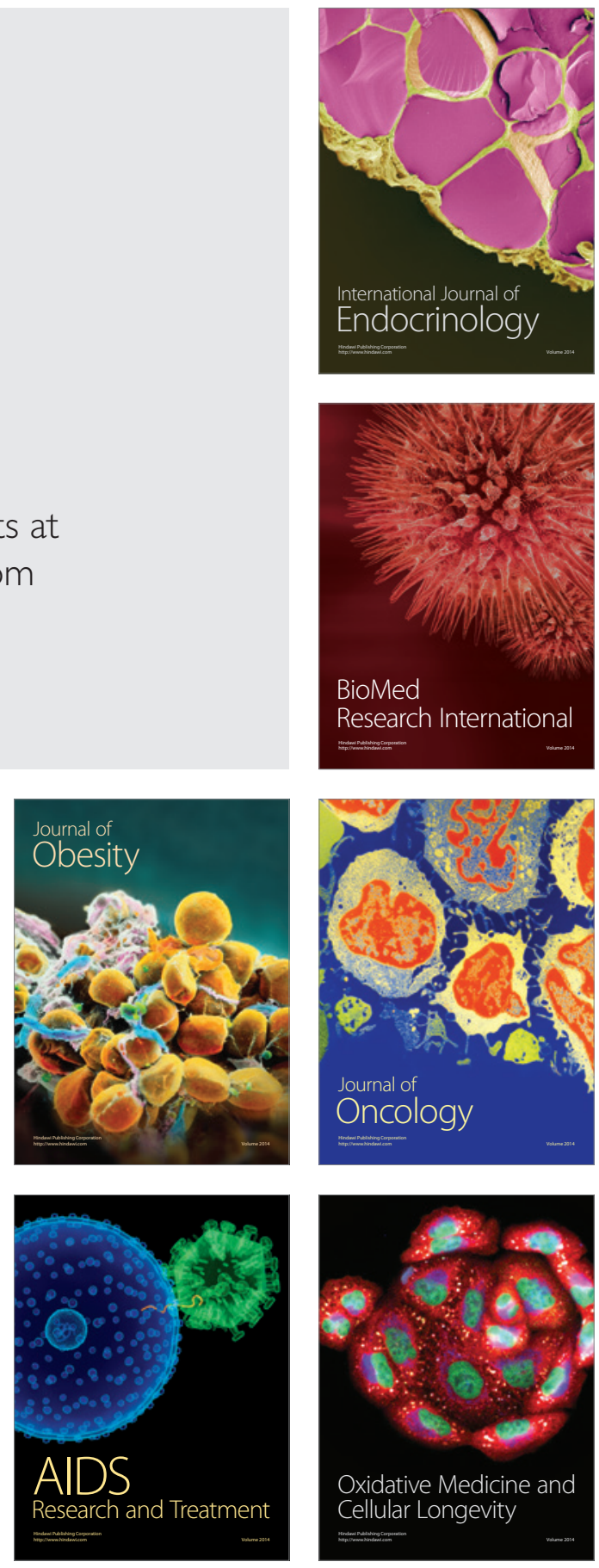